\title{
Esperanza y realidad nacional ${ }^{1}$
}

\author{
P. Jon Sobrino, S. J.
}

\begin{abstract}
Resumen
Este artículo aborda el tema de la esperanza, esa realidad espiritual, subjetiva e invisible. Presenta los símbolos y referentes importantes de ésta que han existido en el país y la suerte que ahora están corriendo. Asimismo analiza lo fundamental de la esperanza popular. Pero, ¿qué importancia tiene? ¿Cómo se consigue? ¿Qué la genera? ¿Para qué sirve? Estas son algunas de las interrogantes que pretende contestar el autor.
\end{abstract}

1. La actual batalla por la esperanza de los pobres

Quizás extrañe que se haya elegido para una Cátedra de Realidad Nacional el tema de la esperanza. Algunos pueden pensar, en efecto, que en estas cátedras y foros semejantes - como los que ofrecen los medios de comunicación- se debe analizar la realidad económica, política y militar, sus causas y consecuencias, todas ellas realidades objetivas, tangibles y verificables, y que configuran la realidad social de las mayorias. La esperanza, sin embargo es una realidad espiritual, subjetiva $e$ invisible, $\mathrm{y}$, se añade, es un realidad de la persona individual, no necesariamente una realidad de los pueblos y de las mayorías. Por ambos capítulos, aun para quienes otorgan importancia a la esperanza - y ciertamente para quienes no tienen ningún interés en ella-, una cátedra de realidad nacional no sería el lugar idóneo para hablar de la esperanza. Habría que remitirla, más bien, al púlpito o al aula universitaria. Pero no todos piensan así.

En primer lugar, la esperanza, aunque realidad subjetiva, es claramente verificable: la esperanza de Monseñor Romero se pudo ver y tocar. Y en segundo lugar, aunque la esperanza - como el amor, la felicidad, la libertad, la fe- es una realidad que formalmente atañe a la persona, a través de la conciencia colectiva configura también, análoga, pero realmente, a los pueblos, a las mayorías: es evidente que en los setenta y ochenta el pueblo salvadoreño era un pueblo sufriente, pero esperanzado, y que ahora en los noventa es un pueblo más desencantado que esperayzado.

1. Este artículo recoge el texto de una conferencia pronunciada en la UCA el 12 de noviembre de 1998, en el IX Aniversario de los Mártires. Aunque ha sido reelaborado, mantiene el tono de discurso oral. 
A esto queremos añadir que la esperanza $-y$ su correlato el desencanto-- no es una realidad inofensiva $e$ inocente. $Y$ para mostrarlo no hay más que ver la formidable batalla que, en estos años, se está librando alrededor de la esperanza de los pueblos. En este mismo auditorio, en la celebración del XV aniversario de Monseñor Romero, en 1995, don Pedro Casaldáliga dijo las siguientes palabras: "Si a un pueblo le quitan la esperanza, le han quitado todo". Para Casaldáliga es obvia la dimensión popular de la esperanza, pero, además, añade que "se la pueden quitar a los pueblos". Y de hecho, la esperanza de los pueblos es objeto de una lucha, y lo importante es saber qué quieren hacer con ella. Dice un economista centroamericano:

Aquellos países que han levantado la esperanza de algo nuevo, como Nicaragua y El Salvador de los ochenta, necesitaban ser no sólo destruidos sino desacreditados y convertidos en una espúrea esperanza de pueblos románticos porque rompían el proceso de homogeneización iniciado con la era Reagan².

La conclusión es que la élite del poder promueve "la geo-cultura de la desesperanza y la teología de la inevitabilidad... La desesperanza es la actitud necesaria para la estabilidad desde la perspectiva del dominador. El desgaste de la esperanza es una necesidad del sistema".

En nuestro mundo se dan, pues, batallas no sólo para apoderarse de materias primas o espacios estratégicos, sino también para apoderarse del "alma de los pueblos", de su "conciencia colectiva". Así, en la actualidad se desea introyectar valores positivos, como la laboriosidad, la competencia laboral, y otros más negativos, como el consumismo y la diversión de evasión. Pero permeándolo todo, sutil o burdamente, se introyecta la resignación, la inevitabilidad, la desesperanza, más que la esperanza, y de esa forma se pretende privar a los pueblos de energía para reaccionar contra la historia actual y revertirla, la cual, como lo recuerda anualmente el PNUD, ha alcanzado cimas de aberración.

De estas afirmaciones generales pasemos a la realidad salvadoreña. Hace algunas décadas hubo una extraordinaria esperanza en el país. La esperanza imumpió como contenido: la utopía de la vida digna y justa de las mayorías. E irrumpió como energía y fuerza subjetiva del espíritu, individual y colectiva, que daba inspiración y ánimo para emprender una praxis transformadora. La utopía movilizó a muchos a trabajar arduamente y a entregar lo mejor de sí mismos a esa tarea. Sólo con ideologías y estrategias, pero sin esa esperanza, no hubiesen sido posibles las revoluciones que ocurrieron en el país ${ }^{4}$.

Eso fue entonces. En la actualidad, tras la esperanza que generaron los acuerdos de paz y el Informe de la Comisión de la Verdad, comenzó a desvanecerse aquélla y apareció el desencanto - como lo demuestran las encuestas-, y las mayorías populares han tenido que aprender a vivir con el desencanto más que con la esperanzas. Además, desde las cúpulas de todo tipo (sin que las cúpulas eclesiales y religiosas hagan lo suficiente por contramestarlo), se introyecta eficazmente la idea de que "ha pasado el tiempo de la esperanza"; más aún, de que "hemos encontrado un camino mejor".

Eso "mejor" que nos proponen es una actitud global que se orienta en la línea del realismo y el pragmatismo, en el vivir ajustados a la realidad, para sacarle todas las ventajas posibles -incluso en favor de los pobres, en la intención de algunos. No hay que negar que ese proyecto de sociedad puede producir algunos bienes, pero presupone que hay poca cabida para la esperanza, pues ésta trae consigo, por esencia, un "desajuste". La "justeza", de la que hablaba Ellacuría, y que hoy se recalca con razón, no tiene por qué oponerse al "desajuste" que produce la esperanza, pero tampo-

2. X. Gorostiaga, "La mediación de las ciencias sociales y los cambios internacionales", en J. Comblin, J. I. González Faus y J. Sobrino, Cambio social y pensamiento cristiano en América Latina, Madrid, 1993, p. 131.

3. Ibid.

4. Hablamos de revoluciones en plural porque, efectivamente, éstas ocurrieron no sólo al nivel pólitico militar, sino también a nivel social (la organización popular), eclesial (el ministerio de Monseñor Romero, las comunidades de base) y teórico (la opción por los pobres en varios ámbitos de la inteligencia, ciertamente en la teología de la liberación).

5. Otra cosa es cómo afectó este proceso - y cómo lo interpretaron - las cúpulas de ambas partes, quienes hasta el momento no acaban de abordar en serio el desencanto popular, preguntarse por qué y trabajar para revertirlo. 
co la puede sustituir, pues ambas cosas responden a ámbitos distintos de realidad. Ambas cosas son necesarias, e ignorar una de ellas es mutilar la totalidad de la realidad. Sin embargo, de realismo y pragmatismo nos hablan hasta la saciedad, mientras que sus defensores muestran sospechas hacia la esperanza por lo que tiene de limitación y peligros. Pero como la esperanza responde a la realidad, sin ella incluso el realismo legítimo degenera en realismo espúreo.

Ese realismo, que prescinde de la esperanza, no es fácil de erradicar, pues nos es impuesto, en muy buena parte, desde fuera y por fuerzas poderosas. En cuanto los seres humanos somos seres de "historia", se nos dice que no hay que esperar nada nuevo ni sustancialmente mejor "pues ya ha llegado el final de la historia"t. En cuanto somos scres de "geografía", se nos dice que sólo hay que esperar la homogeneización, la instalación en la "globalización" — cuyo contenido es decidido por otros.

Existe, pues, una batalla alrededor de la esperanza de los pueblos. En esa batalla, unos están contra la esperanza, a veces en forma directa, como hemos visto, a veces en forma indirecta, introyectando actitudes y expectativas que no la hacen necesaria, sino sospechosa. Pero en la batalla otros están a favor de la esperanza de los pueblos.

Esto es lo que queremos analizar a continuación. Ya ha dicho el Padre Cardenal que la esperanza es escurridiza, y por lo tanto no es fácil hablar de ella. Por ello comenzamos, en forma más descriptiva, presentando símbolos y referentes importantes de esperanza que han existido en el país, y la suerte que ahora están corriendo. $Y$ analizaremos después lo fundamental de la esperanza popular, alrededor de los siguientes temas: (1) la relación entre esperanza y pobres, (2) su contenido utópico, (3) su potencial práxico y su dimensión de gratuidad, (4) lo que produce esperanza.

\section{Referentes de esperanza en El Salvador}

Comencemos con unas palabras, densas y programáticas, sobre la esperanza de los pueblos.

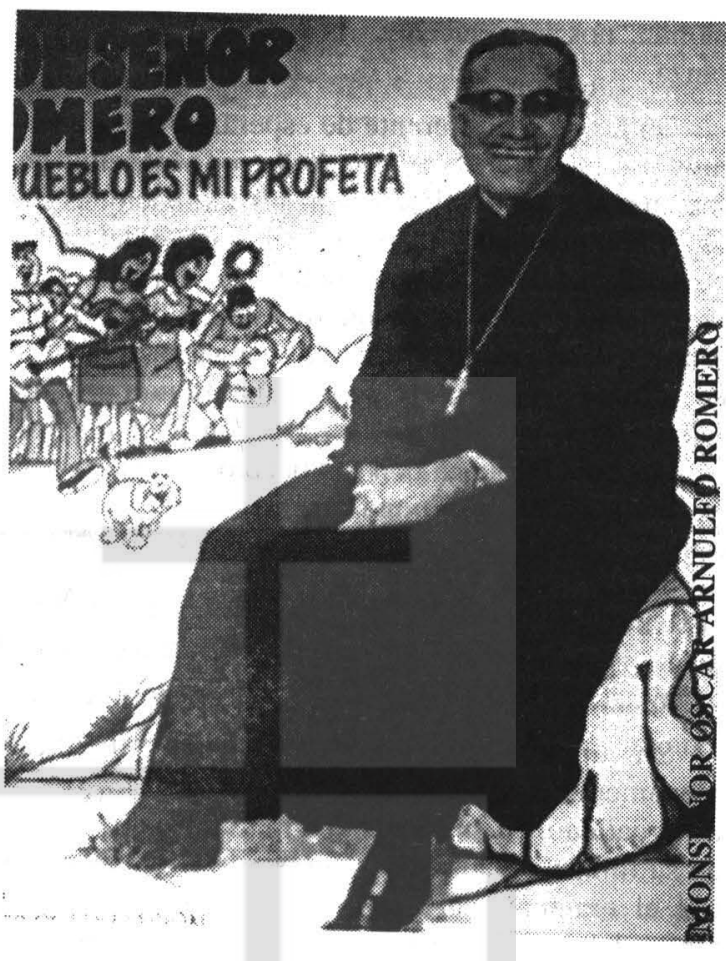

"Muchas veces me lo han preguntado. ¿Hay salida? Y yo, lleno de esperanza, no sólo en Dios, sino en los hombres, digo: 'Sí hay salida"', Monseñor Romero, Homilía del 18 de febrero, 1979.

"Toda esta sangre martirial... lejos de mover al desánimo y a la desesperanza, infunde un nuevo espíritu de lucha y una nueva esperanza en nuestro pueblo... Sólo utópica y esperanzadamente puede uno creer y tener ánimos para intentar con todos los pobres y oprimidos revertir la historia, subvertirla y lanzarla en otra dirección", Ignacio Ellacuría, Barcelona, 27 de enero, 1989; Barcelona, 8 de noviembre, 1989.

"Si a un pueblo le quitan la esperanza le han quitado todo", don Pedro Casaldáliga, UCA, 22 de marzo, 1995.

En lo fundamental estas palabras convergen, $y$ por ello, al analizar los diversos aspectos que men-

6. "El fin de la historia no significa el fin de los acontecimientos mundiales, sino el final de la evolución del pensamiento humano respecto a los principios orientadores... Es el término de la evolución ideológica de la humanidad y de la universalización de la democracia liberal occidental como última forma de gobierno", Francis Fukuyama. Véase Assmann, Hugo, Las falacias religiosas del mercado, edición resumida de Cristianisme i Justicia, Barcelona, 1977, p. 15. 
cionan, nos introducen en la totalidad de la esperanza.

(a) El primer referente de esperanza que queremos presentar es Monseñor Romero. Monseñor no fue ingenuo ni irreflexivo en sus exultaciones de esperanza. Era absolutamente consciente del comportamiento de las fuerzas poderosas del país y de la realidad cruel y aberrante que generaban: "Aquí todo es destrozo, un desastre, y negarlo es ser loco" (7 de enero, 1979). "Existe una pseudo paz, un falso orden, basados en la represión y el miedo" (1.7.1979). "Se juega con los pueblos, se juega con las votaciones, se juega con la dignidad de los hombres" (11.3.1979). "Estamos en un mundo de mentiras donde nadie cree ya en nada" (18.3.1979).

Sin embargo, siendo plenamente consciente de esta realidad, en su vida y en su ministerio hizo central el mantener la esperanza del pueblo. "El grito de liberación de este pueblo es un clamor que sube hasta Dios y que ya nada ni nadie lo puede detener" (27.1.1980). Con lucide $z$ y sin ingenuidad, con el sabor profético de un Isaías, afirmó: "Sobre estas ruinas brillará la gloria del Señor" (7.1.1979).

Según lo que acabamos de cilar, para Monseñor Romero la esperanza fue una realidad ante lodo dialéctica, es decir, lo que surge en presencia de y en contra de graves males históricos. De ahí que, en terminología paulina, la esperanza sea "contra esperanza". Su contenido, la utopía, se constituye en contra de la realidad opresora y deshumanizantc. Y su fuerza subjetiva se constituye en contra de la desesperación, la resignación o el desencanto, según los casos. Y por cierto, esa dimensión dialéctica de la esperanza, el tener que "hacer contra", es lo que la relaciona esencialmente con los que están abajo en la historia, cargando con clla, porque la historia está contra ellos. La esperanza es en directo una realidad de pobres, empobrecidos y víctimas.

Por su carácter esencialmente dialéctico, la esperanza no está en continuidad mecánica con el presente, no es puro producto de un cálculo ni extrapolación para el futuro de las posibilidades del presente —en donde "todo es destrozo", como dice Monseñor. Tampoco es puro optimismo que disimula la verdad de las cosas y su dureza. $Y$, por supuesto, no es producto de una propaganda que colorea la realidad a favor del que la mira.

Para Monseñor Romero la esperanza es la convicción - fe, en definitiva- de que la última palabra sobre la realidad, aunque muchas veces no se manifieste, sino que se oculte, la tiene la bondad y el bien. Conceptualizándola desde el futuro -que es, formalmente, el ámbito temporal de la esperanza- es la convicción de que la realidad es, también, "promesa": el futuro puede ser portador de bondad, de humanización, de plenitud. En términos religiosos, la esperanza afirma que la última palabra sobre la historia y sobre los pueblos la tiene Dios. Es éste un extraño Dios, ciertamente, un Dios muchas veces silencioso y sin-palabra, inactivo e impotente, como aparece en la cruz de Jesús, "Dios crucificado". Pero un Dios, también, que crea "nuevos cielos y nueva tierra", que devuelve a la vida a Jesús, una víctima. Ese Dios mantiene viva la más primigenia de las esperanzas: "que el verdugo no triunfe sobre la víctima".

Esa fe-esperanza no mueve al puro "esperar", sino a la praxis, que en el caso de Monseñor Romero fue realmente prodigiosa y plurivalente: praxis pastoral, evangelizadora, profética, doctrinal, que incidía profundamente en la configuración histórica y social de la realidad salvadorena; y también, en ocasiones importantes, en el ámbito directamente político: su propuesta de diálogo nacional, su mediación en la crisis de la Junta de gobierno... Esa, y no cualquier praxis, reforzaba la esperanza popular.

Por último la esperanza de Monseñor Romero, la suya personal y la que comunicaba a otros, provenía de y recogía la esperanza, latente o patente, del pueblo - más la fe en Dios, ya mencionada. Así escribía Ignacio Ellacuría:

Sobre dos pilares apoyaba su esperanza: un pilar histórico que era su concimiento del pueblo al que él atribuía una capacidad inagotable de encontrar salidas a las dificultades más graves, y un pilar transcendente que era su persuasión de que últimamente Dios es un Dios de vida y 
no de muerte, que lo último de la realidad es el bien y no el mal?.

En su tiempo El Salvador fue un pueblo de esperanza, y así lo vieron muchos en todo el mundo. Sólo hay que añadir que esa esperanza no fue de todo el pueblo por igual, sino que fue esperanza de las mayorías, de los pobres.

(b) El segundo referente es Ignacio Ellacuría. Es bien sabido que Ellacuría fue todo menos irracional, ingenuo y de lenguaje melifluo. Es sabido también - sobre esto volveremos- que para la eficacia que buscaba en la praxis insistía en el realismo (que incluía la negociación cuando era necesaria). Y, sin embargo, para expresar lo que mueve la historia a la manera humana y lo que apunta a la manera más cabal de ser humanos mencionó también explícitamente y centralmente, como ingrediente esencial de una sociedad humana, la esperanza. No hay que olvidar que su último escrito teológico, de agosto de 1989 - verdadero testamento- versa sobre profetismo y utopía, con sus correlatos de denuncia y esperanza. Y ochos días antes de ser asesinado volvió a proclamar, sin nada de retórica, la imperiosa necesidad de ambas cosas.

De esa esperanza recalca que no es una esperanza simplemente expectante, sino decididamente activa, práxica y agonista, es decir, luchadora - lo cual, conocidamente, es coherente con su antropología de la praxis. Es una esperanza que expresa la dirección que debe tomar la realidad: "revertir la historia, lanzarla en otra dirección", palabras éstas hoy silenciadas, Ioleradas quizás por provenir de un mártir, pero palabras en definitiva "polílicamente incorrectas" (como se dice en Estados Unidos), malsonantes para la ortodoxia del sistema. Recalca tambićn el potencial solidario de la esperanza, pues ésta tiene la virtud de salvar distancias y unilicar a diversos grupos sociales: Irabajar "con todos los pobres y oprimidos".

La meta de esa historia revertida, "palas arriba", es la "civilización de la pobreza", sólo la cual puede triunfar sobre la deshumanización del pobre, en forma de muerte, violencia e indig- nidad, y sobre todo sobre la deshumanización de los empobrecedores, en forma de sinsentido, mentira y encubrimiento perennes para ocultar su verdadera realidad. Esa civilización de la pobreza (emparentada estrechamente con" la civilización del trabajo) es la actualización de la utopía cristiana: "el reino de Dios", el cual es, por esencia, "sólo para los pobres".

Por último, Ellacuría insistió hasta el final en que la entrega de la vida - la sangre y el amor- trae esperanza, salvación, según la paradoja cristiana. Ellacuría lo analizó con gran hondura y creatividad intelectual (escribió pioneramente sobre "la salvación que trae el pueblo crucificado") y lo vivió en su persona (murió mártir, y no por casualidad, en el servicio a las mayoría pobres, no a una abstracta negociación). La realidad de los pobres, la entrega de la vida, el amor, los mártires, serán para Ellacuría, con diversos matices, lugares y fuentes de esperanza.

(c) Hasta ahora hemos mencionado a dos referentes conocidos e importantes de la esperanza del pueblo salvadoreño en el pasado. Pero, aun aceptado lo dicho, pudiera decirse que "las cosas han cambiado", y que, por tanto, aunque sean de admirar, no hay por qué recordar e imitar a Monseñor Romero y a Ignacio Ellacuría en su esperanza. Por eso queremos ofrecer ahora otro testimonio en favor de la esperanza en nuestros dias, el de don Pedro Casaldáliga, buen conocer de las tres últi-

7. "La UCA ante el doctorado concedido a Monseñor Romero", ECA, 437, 1985, p. 174.

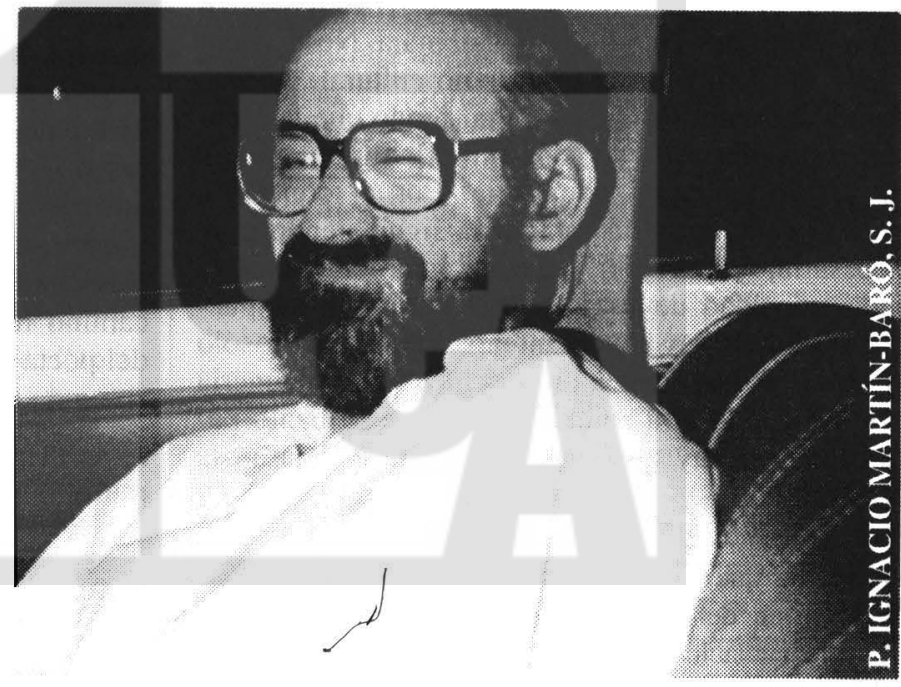


mas décadas del continente y de nuestro país, del antes y del después de la guerra.

Pues bien, don Pedro Casaldáliga "sigue" hablando de esperanza. Aun teniendo en cuenta las novedades que han sobrevenido (algunas positivas, fin de la violencia bélica y del militarismo sobredeterminante, coexistencia pacífica de las fuerzas políticas, intentos de humanización a través de los Acuerdos, épocas buenas de la procuraduría de Derechos Humanos...), y teniendo en cuenta, por otra parte, la pobreza, la violencia, la deslatinoamericanización cultural, las imposiciones del Fondo Monetario y del Banco Mundial, la deuda externa - todo esto en tiemos de normalización-, sigue insistiendo en la necesidad y centralidad de la esperanza de los pobres.

Casaldáliga acepta con naturalidad que "las cosas han cambiado", añade incluso que debieran cambiar algunas actitudes de antaño de la izquierda, civil y eclesial. Pero insiste en lo que no ha cambiado", y analiza el significado del cambio, para no sacar conclusiones precipitadas ni menos equivocadas -que es lo que hoy ocurre con frecuencia. No ha cambiado la pobreza creciente ni la violencia inmensamente grande. No ha cambiado del todo el ascsinar al que estorba, como lo muestra lo ocurrido a Monseñor Gerardi en Guatemala. No ha cambiado la corrupción ni el despojo cultural. No han cambiado, pues, las cosas de tal modo que la esperanza popular sería ya cosa superflua u optativa, y en cualquier caso secundaria. Por el contrario, para Casaldáliga esta esperanza sigue siendo muy necesaria, y por ello pone en guardia contra la monstruosidad de "quitar la esperanza a un pueblo". Lo que hay que plantearse, pues, no es sólo si hay o no esperanza, sino si hay que mantenerla o si no queda otra solución que el desencanto paralizante, si hay que luchar por ella o dejárnosla arrebatar.
Visto desde el reverso de la esperanza -el desencanto-, Casaldáliga desenmascara a los que preguntan —con buena voluntad, pero sobre todo con disimulado alivio- qué ha sido de aquellas cosas que en su día generaron esperanza. Y se maravilla de que hoy estorben precisamente quienes han generado mayor esperanza, los mártires. Escribe Casaldaliga:
Algunos creen que ya es hora de cambiar nues- tros paradigmas. Y hasta les parece que los már- tires estorban en esta memoria postmoderna o postmilitante. $\mathrm{Al}$ aire de la decepción, amigos y enemigos vienen lanzando tres preguntas pro- vocadoras: ¿qué queda del socialismo?, ¿qué queda de la teología de la liberación?, ¿qué queda de la opción por los pobres? Espero que no acabemos preguntándonos qué queda del evangelio".

Añadimos nosotros: "esperamos que no acabemos preguntándonos qué queda de la esperanza", como si fuese cosa de otros tiempos - de facto y de iure.

Sobre la centralidad de la esperanza don Pedro Casaldáliga ha escrito muchas páginas. En un breve poema, titulado "Yo me atengo a lo dicho" recorre todas las cosas importantes para los seres humanos y para los creyentes, y por este orden: justicia, humildad, libertad, fe cristiana. Y termina: "Y, en todo caso, hermanos, yo me atengo a lo dicho ¡la Esperanza!"'10. Y la fuente de esa esperanza es el pueblo. En otro poema, "Camino que uno es", corrigiendo a Machado desde el tercer mundo, descentra el caminar sólo con un mismo, caminando "para que otros caminantes puedan el camino hallar". Y concluye con la incorporación del poeta al pueblo: "Haz del canto de tu pueblo el ritmo de tu marchar""l.

(d) Hemos presentado a tres referentes de esperanza. Todos ellos fueron, ellos mismos, personas

8. Piensa que así lo muestran los informes del PNUD, de los que dice lo siguiente: "Afortunadamente, ya el informe del Programa de las Naciones Unidas para el desarrollo ha pasado a ser casi un manual de concienciación", La Escala de Jacob. Circular fraterna, enero, 1999.

9. "El cuerno del Jubileo", Carta a las Iglesias, 393, 1998, p. 8.

10. En Cantares de la entera libertad, Managua, 1984, p. 27.

11. En ibid., p. 47. 
de esperanza (hablamos en pasado para referirnos a Monseñor Romero e Ignacio Ellacuría, aunque incluimos a don Pedro Casaldáliga en el presente) y los tres fueron referentes de la esperanza del pueblo salvadoreño. Los tres tuvieron una esperanza con contenido religioso, pero los tres generaron esperanza con contenido histórico. Ninguno de ellos ha sido ingenuo, ni menos insensato. Sabían bien que sólo con esperanza no se construye la familia humana en dignidad, vida y justicia, y por ello se dedicaron a muchas otras tareas históricas; en su caso, tareas pastorales, de derechos humanos, asistencia social, universitarias, intelectuales, políticas. Pero sabían también que sin esperanza no se ponen en marcha los procesos de cambios necesarios (la esperanza como fuerza del espíritu), ni se les da la dirección adecuada de humanización (la esperanza como utopía). Los tres fueron personas insignes, escritores, cuyas obras siguen siendo leídas y estudiadas. Dos de ellos, Monseñor Romero y don Pedro Casaldáliga, fueron nominados al Premio Nobel de la Paz; Ignacio Ellacuría recibió numerosos reconocimientos internacionales. Los tres fueron muy por delante de otros líderes en orientar caminos de humanización.

Y todavía falta por decir lo más importante. Los tres se mantuvieron firmes hasta el final, Monseñor Romero e Ignacio Ellacuría murieron mártires, y don Pedro Casaldáliga no lo fue por error del asesino, quien, equivocadamente, disparó contra su compañero, el P. Joao Bosco, S.J., cuando fueron a protestar a una comisaría de policía en que eran torturadas unas mujeres. Como consecuencia de todo cllo, los tres son muy queridos, no sólo admirados, viven en el corazón de los pobres. Cuando murió Monseñor, el pueblo lo lloró "como se llora a un padre". Y esto nos parece muy importante al analizar la esperanza de los pueblos.

Si csto es así, si verdaderamente los mejores han sido seres humanos de esperanza - y la lista comienza desde atrás, Jesús de Nazaret, Juana de Arco, José Martí, Gandhi, Dorothy Day, Desmond Tutu - y la han comunicado a otros, entonces, por honradez con lo real hay que decir que la esperanza no es cosa de ingenuos e inconsultos, de románticos y obsoletos. Y como su esperanza perso-

nal se nutrió de la del pueblo y, a su vez, se desbordó en él, devolviéndosela, la esperanza configuró colectividades, grupos, pueblos. No se puede despachar con facilidad la esperanza de un pueblo, ni menos ridiculizarla, sin faltar a la honradez con lo real.

Todo esto debiera hacer pensar a sociedades como las nuestras que ahora parecen poder vivir muy tranquilamente sin esperanza, porque los acuerdos de paz y las amnistías ya habrían puesto las bases suficientes para humanizar la sociedad. Se reconoce que falta mucho por hacer y que hay que desarrollar actitudes de diálogo, tolerancia, lahoriosidad, cultura de la paz, pero no se menciona ya la esperanza.

\section{Qué ha pasado con los referentes de la espe- ranza}

Los mejores, como acabamos de ver, hicieron de la esperanza algo central para los pueblos. Pero también de ellos se cuestiona si deben ser tenidos en cuenta o si es mejor silenciarlos. Y si se les quiere tener en cuenta, en qué: en la esperanza, o en otras cosas, aunque sean importantes, como el realismo y el pragmatismo. En ese contexto quisiera hacer algunas reflexiones sobre lo que está ocurriendo en la actualidad con los referentes de esperanza, con los que hemos mencionado y con tantos otros, mártires y caídos, personas, grupos e instituciones comprometidas, comunidades populares. 
(a) La sospecha contra una esperanza con raices religiosas. En nuestro país no se habla mucho de ello, pero quisiera recordar que las personas mencionadas son personas religiosas, aunque han propiciado esperanzas históricas y populares - además de otras específicamente religiosas. Esto para nada niega que personas no religiosas no tengan esperanza ni fomenten las esperanzas populares. En ningún sentido se afirma, pues, que lo religioso tenga el monopolio de la esperanza. Pero también es verdad que algo parece haber en lo religioso que abre a la esperanza. Y más que otras realidades.

En la historia, han sido las religiones, más que las filosofías y las teorías políticas, las que, en general, han planteado el problema de la esperanza, y con la radicalidad (y también con los peligros) que le es propia a lo religioso. El humus de la esperanza - la tierra en que crece- sigue siendo muy frecuentemenre lo religioso. La religión biblica, por ejemplo, con su esperanza mesiánica, sigue generando normalmente más esperanza que la mera tradición democrática, con sus promesas de igualdad.

Mencionamos esta relación entre religión y esperanza porque, desde diversas pespectivas, es vista como problemática. Por una parte se recalca hoy el potencial conflictivo de lo religioso. Lejos de acusar a la religión de ser "opio", se la teme ahora por ser luente de conflictos — sospecha que se expresa sobre todo en el primer mundo. Esto suele fundamentarse, apuntando a que lo religioso (al menos en la tradición bíblica) insiste en la dimensión dialéctica y duélica de la realidad. Además, la radicalidad del profetismo y utopía, que le es propia a la religiones abrahámicas, pueden generar agresividad - como en estos días aparece en el lánatismo religioso del mundo musulmán.

En este contexto, aun admitiendo la necesidad y hondad, en principio, de la esperanza, se puede sospechar que una esperanza activa y dinámica (los buenos deseos siempre se toleran) puede Iransformarse en euforia y llevar a la praxis y al conflicto, como lo habría hecho en décadas pasadas. La conclusión es que hay que introyectar en las mayorías valores más acordes con las sociedades democráticas actuales y menos conflictivos que la esperanza y otros valores religiosos. Aquéllos serían hoy el diálogo y la tolerancia, el pragmatismo y el realismo $-y$, por supuesto, la laboriosidad y competitividad, mientras que una reli- giosidad que genera esperanza y conflicto puede ser vista con sospecha.

Por otro lado, también existe hoy - y extendidamente-orra versión de lo religioso, distinta y aun contraria a la anterior por lo que toca a configurar la sociedad. Es la religiosidad centrada en el individuo y su interioridad, cuya esperanza está puesta en el más allá, mientras que abandona la historia a su miseria: movimientos pentecostales, carismáticos, neocatecumenales, y otros movimientos pastorales que van alejándose cada vez más de Medellín. No es ahora el momento de analizar este fenómeno ni sus causas (endógenas sobre todo, aunque también exógenas) ni sus consecuencias (solución de problemas personales importantes, por un parte, despolitización por otra). Pero, por lo que toca a la esperanza social, esta religiosidad prácticamente la hace desaparecer y por ello es tolerada por las actuales democracias, ya que no confronta a la Iglesia con los conflictos de antaño ni la hace reaccionar como antes - aunque la Iglesia, de palabra, reconozca e insista en que existe un gravísimo conflicto social.

La conclusión es que, para generar esperanza, entre otras cosas hay que volver al potencial que liene lo religioso, sobre todo en países sociológicamente religiosos y en los que luvo impacto la corriente de Medellín. Si se repite el peligro de agresividad que tiene lo religioso y que mejor será atemperarlo con valores democráticos más pacíficos, piénsese que lo democrático - en sus formas reales actuales - lleva consigo el peligro contrario de adormecer al pueblo, y por ello bueno será la "sacudida" religiosa para no seguir "en sueño tan letárgico dormidos", que decía Antonio Montesinos. El "des-ajuste" de la esperanza sigue siendo necesario - venga de donde venga, y aunque provenga de lo religioso.

(b) El silenciamiento que se ha cernido sobre los referentes del pasado. La segunda reflexión va más allá de la problemática de la esperanza, pero la incluye. Me refiero a la necesidad de mantener vivo y recuperar "lo mejor del pasado" ante la clara tendencia a prescindir de él, cuando no a renunciar a él o a rechazarlo. Unos dicen, con razón, que "las cosas han cambiado", y que, por lo tanto, realidades como compromiso, profecía, utopía $-y$ entre ellas la esperanza- no tienen por qué estar ya muy presentes en la escena pública, ni menos debe ser centrales. Sólo que quien así piensa, debe preguntarse también si "la condición humana ha 
cambiado", y si no habrá que hacer algo para superar la actual situación de desencanto.

El tan repetido "las cosas han cambiado" es una tautología, y lo que hay que analizar es si es una tautología fructífera o una tautología estéril. Si se analizan en serio los cambios, si se los prioriza según lo que se gana y se pierde con ellos, quiénes mejoran o no mejoran, a qué de humano abren y a qué cierran, entonces la tautología puede ser fructifera. Pero si no se analizan los cambios desde la perspectiva de las mayorías, la tautología es estéril. Peor aún, puede usarse para paralizar cambios realmente necesarios y para encubrir el presente.

Otra razón que se aduce para silenciar el pasado, en concreto en nuestro país, es que "hay que sanar las heridas". Lo que se pretende es importante, y por ello hay que trabajar. Pero que el mejor medio para ello sea el olvido es cuestionable, sobre todo cuando no se trata de heridas producidas por un conflicto simétrico entre dos partes (una guerra), sino de heridas de un conflicto asimétrico entre víctimas y verdugos (represión, terrorismo). En esta situación, es difícil que las víctimas olviden pura y simplemente, como lo muestra el alboroto alrededor de Pinochet: después de años de olvido, fingido e impuesto, al menor soplo sc conmueve todo el edificio. Es decir, no ha habido olvido. Y es que para sanar heridas lo importante no es el acto negativo de olvidar que se pide a las víctimas, sino el acto positivo de reconciliación que se pide a todos. $\mathrm{Y}$ esto - visto desde las víctimas - tiene la siguiente secuencia: petición de perdón por parte del verdugo, otorgamiento del perdón por parte de las víctímas y aceptación de ese perdón por parte de los verdugos - así acaece la reconciliación. Se trata, pues, de integrar adecuadamente el pasado en el presente, no de ignorarlo ni de declararlo irreal por decreto.

En este sentido, sorprende la lógica (le) olvido y cl pacto de silencio que rcinan en la realidad política del país sobre personajes a los que se invocaba hace muy pocos años - recordemos a
Farabundo y Sandino ${ }^{12}$. Si hubo exageración, limitación o error al hacerlo, dígase con sencillez. Pero el actual silencio, al parecer tan dogmático como las anteriores invocaciones, da en qué pensar, sobre todo porque en ese silencio se incluye a caídos, héroes y mártires, muchos de los cuales merecen estar muy presentes y tienen mucho que aportar para humanizar el presente.

Con Monseñor Romero no ha pasado exactamente lo mismo. Gente del pueblo, sacerdotes y varios obispos, muchos de los que trabajan por la verdad, la vida, la justicia, la dignidad y la paz, lo recuerdan en verdad. Siguen celebrándose sus aniversarios y publicándose sus escritos. Pero también es cierto que no todas las altas instancias eclesiales se remiten a él, lo cual ocurre, paradójicamente, cuando se promueve oficialmente su canonización. En mucha de la pastoral y la predicación pareciera que no hubiera existido. Y por lo que toca a las fuerzas políticas, militares y sociales, con contadas excepciones, su silencio, que dura ya veinte años, clama el cielo.

Esta cultura del olvido es mala y deshumanizante, porque de esa manera las sociedades y los pueblos "se quedan sin referentes". San Ignacio decía en sus Ejercicios Espirituales que en la vida personal es necesario un "principio y fundamento" -y algo semejante ocurre con los pueblos. "Principios" son realidades que por su naturaleza gene-

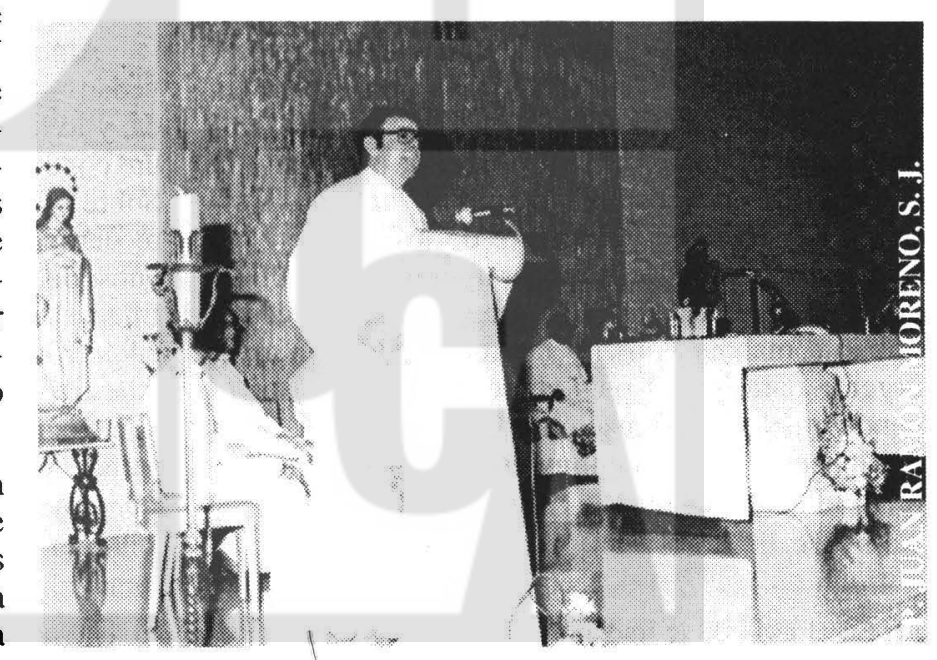

12. Una anécdota de otro país. En España un editor buscaba que un miembro del partido socialista escribiera un prólogo para presentar una moderna traducción de las obras de Gramsci. No sé si llegó a encontrar a alquien. Pareciera como si la actitud fuese. "¿Gramsci? ¿Quién es ése?” 
ran, "principian" otras cosas. "Fundamento" son realidades sobre lo que se puede edificar con solidez y a la larga. Y eso también es necesario en la realidad social.

En la tradición bíblico-cristiana esto es esencial. A diferencia de la griega y su eterno retorno, la tradicion bíblica desarrolló una visión de futuro, la utopía final. Y, sin embargo, es también la tradición que más radicalmente remite al pasado para encontrar referentes fundantes. A lo largo de todo el Antiguo Testamento resuena el "recuerda Israel", que remite al éxodo. En el Nuevo Testamento resuena el "hagan esto en recuerdo mío", que remite a Jesús de Nazaret. Y a quien se le pide recordar no es sólo ni principalmente al individuo, sino a todo un pueblo. Teniendo en cuenta los referentes del pasado y los referentes que se generan a lo largo de la historia transcurre la vida de los pueblos ${ }^{13}$. Sin ellos las sociedades quedan sin raíces, sin pasado que las catapulte adecuadamente al futuro.

\section{Digamos, para termi-} nar este apartado, que si Monseñor Romero, Ignacio Ellacuría y personas como ellos ya no son referentes válidos para la sociedad salvadoreña ¿quiénes lo son? ¿O será que los seres humanos ya no necesitamos símbolos - personas y grupos - para saber por dónde caminar? ¿Bastará para ello la "gobalización impersonal", que fungiría hoy como la antigua "mano invisible", o como el antiguo "destino", la necesidad, la ananke de los griegos? ¿O será que el "final de la historia", que ya ha llegado, hace irrelevantes estas preguntas? En nuestra opinión, mantener, recuperar referentes, es vital y urgente para que el país no se deslice más por la pendiente de la resignación y la trivialización de la existencia. Y esto vale muy especialmente para los referentes de esperanza. (c) La exaltacion del pragmatismo. La tercera reflexión es más concreta, y trata sobre cómo se recuerda a Ignacio Ellacuría. Hay unos que, según sus posibilidades, tratan de proseguir su obra intelectual, universitaria y cristiana. Otros, por el contrario, simplemente lo silencian - y en privado lo seguirán criticando. $Y$ hay otros que lo invocan para encontrar apoyo para posturas ideológicas y comportamientos políticos determinados. Pues bien, aceptando que Ellacuría puede ser referente válido de muchas cosas, creemos que se está dando el fenómeno de presentarlo, casi exclusivamente, como referente de realismo y pragmatismo.

Ellacuría fue una persona, un pensador y un cristiano multifacético, profundo y creativo. Por ello puede ser invocado para varios fines, pero también hay que poner en guardia sobre el peligro de reduccionismo de que puede ser objeto ${ }^{14}$. Así, al hablar de él como "pragmático" no se tiene por qué negar que fue también referente de esperanza, de profetismo y utopía. Pero al minusvalorar esto último y supervalorar su pragmatismo, se devalúa grandemente su ser referente de esperanza.

Algunos insisten hoy en presentar - como novedad - al Ellacuría negociador de la última época, y lo hacen al menos implícitamente, para poner un contrapunto al "primer" Ellacuría, el radical. Sobre eso sólo quisiera decir, si se me permite un recuerdo personal, que ya en febrero de 1981 , después del fracaso de la llamada ofensiva final, Ellacuría habló de la absoluta necesidad de la negociación (la $E C A$ de abril-mayo de ese año da muestra de ello) y en momentos, por cierto, en que la negociación no era aceptada por ninguna de las partes. Y más de fondo quisiera recordar que Ellacuría insistía, ciertamente, en la justeza con que

13. En el caso de la tradición cristiana, digamos, por ejemplo, qué referente fundante es el evangelio de Marcos y relerente nuevo es Medellín. Entre ambos se debe desarrollar una dialéctica fructífera para caminar adecuadamente en la historia que, a la postre, es lo decisivo.

14. La manipulación de Ellacuría se dio, y muy pronto después de su asesinato, fuera del país. Muy pronto se le presentó como justificador teórico de la violencia, del tipo de ETA, aunque él mismo la hubiera condenado explịcitamente en un artículo de la revista Concilium en 1988. 
había que enfrentar la realidad - concepto éste de justeza que elaboró con gran creatividad teóricay no sólo en la justicia hacia la que había que transformarla. Pero dicho esto, no seria correcto reducir a ello la persona de Ellacuría.

En mi opinión Ellacuría fue, ante todo, un radical. Quería revertir la historia, y ese fue el horizonte que mantuvo hasta el final, como lo dijo ocho días antes de ser asesinado. Esa radicalidad no significaba ni ligereza teórica ni irresponsabilidad práxica, sino que era fruto de la seriedad con que enfrentaba la realidad, y por ello Ellacuría exigía simultanear las siguientes cuatro cosas. Objetividad para acercarse a la realidad, captarla y analizarla tal cual es — de lo cual, solía decir, se desprende la opción por los pobres como exigencia objetiva de la realidad. Realismo para dar los pasos que son ajustados a las posibilidades de la realidad, pero entendidos éstos como pasos, es decir, como aquello que por definición debe ser alcanzado y sobrepasado para llegar a lo que realmente se pretende y que nunea debe ser perdido de vista. Profecia para denunciar los males de la realidad sin acomodarsc a clla, hacićndolo categóricamente porque la maldad se muestra con ultimidad y estando dispucsto a cargar con el peso de esa realidad. Utopia, por último, para proponer aquello a lo que apunta la negación de los males, y, más allá de ello, para proponer el horizonte de planificación personal y social -y dejándose cargar por la esperanza que acompaña a la utopía.

En mantener la necesidad de estas cuatro cosas y de simultanearlas consiste, en mi opinión, la genialidad y la grandeza de Ellacuría. Pero hay que insistir en lo fundamental. Lo que ponía en movimiento, lo que otorgaba dinamismo, lo que daba dirección a cada una de ellas y lo que movía existencialmente a la difícil combinación de todas ellas, era el "dolor" que le causaba el sufrimiento de las víctimas, sufrimiento que nunca relativizó ni con el que nunca pactó, y la correlativa compasión, a la que él llamó "servicio".

Hablar del realismo de Ellacuría significa, ante todo, hablar del impacto real que le causó el dolor del pucblo. Esa realidad — no, en lo fundamental, aprioris filosólicos o tcológicos- es también lo que le hizo ver la necesidad de la profecía y su denuncia, y de la utopía y su esperanza. En Ellacuría, pues, no se oponían, sino que convergían la justeza en la línea de la objetividad, con su realismo, la justicia en la línea de la praxis, con su

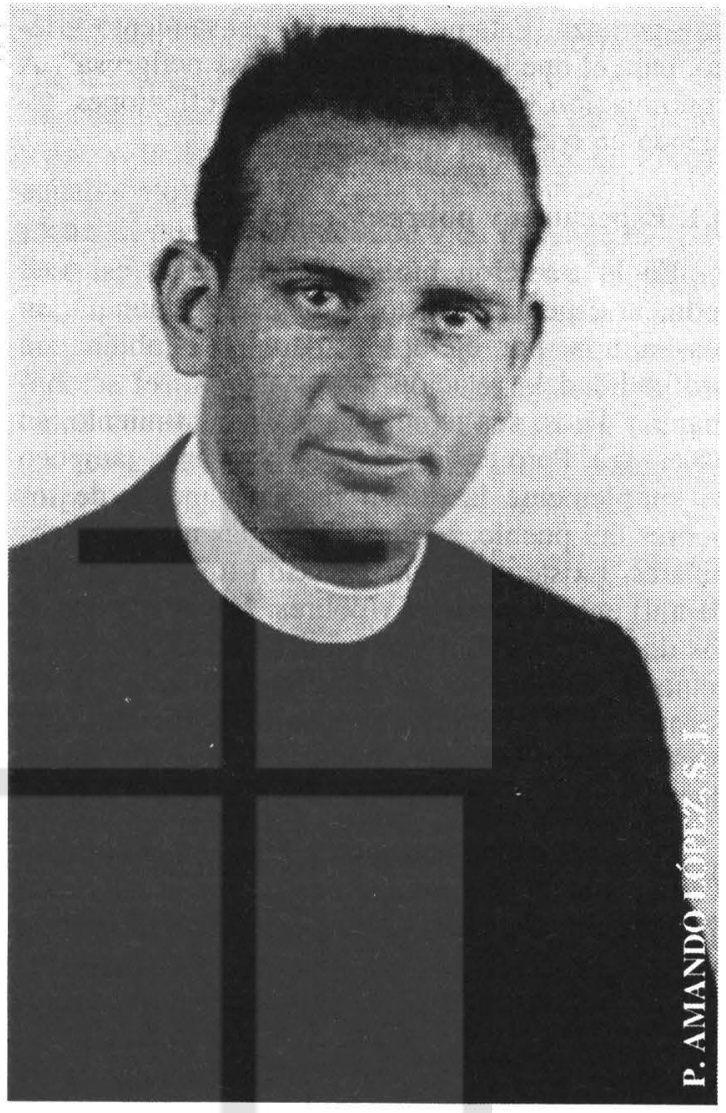

denuncia, y el des-ajuste en la línea de la esperanza, con su utopía. Ellacuría puede ser, pues, referente de varias cosas, pero no hay que mutilarlo. En la actualidad, las mayorías populares lo necesitan y también como referente de esperanza.

\section{La esperanza de los pobres}

Analicemos ahora la esperanza. Su condición de posibilidad es la misma naturaleza del ser humano el "inquieto corazón" que decía san Agustín, su capacidad de ver el futuro como promesa y de entregarse a él confiadamente. Pero queremos analizar la esperanza específica de los pueblos en nuestro contexto presente. Para ello vamos a retomar lo fundamental de la tradición bíblica que ha influido, además, en el pasado reciente de nuestro país. Pues bien, aunque según esta tradición los seres humanos hayan pasado por momentos de duda y desencanło -como lo muestra la literatura sapiencial- la es esencial la fe en un futuro plenificador ("Ios nuevos cielos y la nueva tierra" de Isaías y el Apocalipsis), y de ahí la centralidad de 
la esperanza. Estamos lejos del pensamiento griego, para el que la esperanza es "cosa peligrosa". A continuación vamos a hacer cuatro reflexiones, teniendo en cuenta la situación actual.

\subsection{Esperanza y pobres}

En la tradición bíblica la esperanza es, ante todo, la esperanza de todo un pueblo, aunque en los salmos, por ejemplo, aparezca también con profundidad la relación personal entre el ser humano y Dios, sus temores, su arrepentimiento, su esperanza. Pero en la Biblia la esperanza tampoco es simplemente la de un pueblo, sino la de los pobres del pueblo, es decir, la de las mayorías populares. Existe, pues, una relación (quasi-transcendental) entre esperanza y pobres. Y eso aparece en los dos grandes símbolos bíblicos de esperanza: el reino de Dios y la resurrección. Aunque sea en forma de digresión, analicémoslo brevemente, pues establece el hecho fundamental del que se deducen otras dimensiones de la esperanza.

Por lo que toca al reino de Dios, en el Antiguo Testamento la esperanza consiste en la aparición de un rey justo, lo cual significa la aparición no de un rey "imparcial" hacia todos, sino de un rey "parcial" a los pobres y los débiles: "por fin la vida del pobre será posible", porque, en el lenguaje religioso de la época, Dios será su protector. Y en el anuncio de Jesús los destinatarios son claramente los pobres: el reino de Dios que se acerca es "únicamente para los pobres"15, lo cual supone un trastrueque de la realidad social, como dice Jesús en las parábolas: "los últimos serán los primeros". El reino de Dios es, pues, ante todo, un símbolo de esperanza popular:

Jesús dio expresión religiosa a la situación real de la inmensa mayoría del pueblo judío del siglo I. El Dios del reino expresa la esperanza real de un pueblo en grandes dificultades materiales, sumido en una crisis de identidad cultural y política. Por eso Jesús suscitó un indudable eco popular a lo largo de todo su ministerio ${ }^{16}$.

Lo que acabamos de decir sobre el reino de Dios es suficientemente conocido, pero quizás convenga cxtenderse un poco más en el otro símbolo bíblico de esperanza: la resurrección. Y para comprenderlo es importante conocer cómo surge la esperanza en la resurrección.

En el Antiguo Testamento, después de siglos de vivir sin una fe clara en la resurrección de los muertos, ésta surge para responder a un escándalo teologal fundamental: el poder de la injusticia parece ser mayor que el de Yahvé. Y la respuesta, que surge en el movimiento apocalíptico en los dos siglos anteriores al Nuevo Testamento, es que Yahvé sí hará justicia, resucitará a las víctimas.

Esta esperanza surgirá de forma inequívoca en la situación de la persecución de que fueron objeto muchos fieles israelitas bajo Antíoco IV Epifanes, muchos de los cuales fueron matados con crueldad. En ese contexto aparece la redacción final del libro de Daniel en que se menciona claramente, y como única vez en el Antiguo Testamento, la resurrección de los muertos, de los caídos bajo la persecución: "muchos de los que duermen en el polvo (sheol) despertarán: unos para la vida eterna, otros para ignominia perpetua" $(12,2)$. "Resurrección" es pues un símbolo de esperanza para las víctimas, no para todos. $Y$ hay que añadir otra cosa fundamental: la resurrección nunca es presentada como la de un individuo, sino como resurrección de una colectividad ${ }^{17}$.

El Nuevo Testamento recoge y lleva a plenitud esta esperanza a propósito de la resurreccion de Jesús. En la primera predicación cristiana, aunque de forma estereolipada, la resurrección de Jesús fue formulada en un esquema dialéctico-antagónico, como aparece en los seis discursos programáticos de los Hechos. "Ustedes lo mataron clavándole en una cruz... A éste Dios le resucitó liberándole de los dolores del Hades, pues no era posible que quedase bajo su dominio" $(2,23 \mathrm{~s}$ par). La resurrección es, pues, lo que acaece no a cualquier cadáver, sino a una víctima. Por ello, la esperanza de resurrección es de las víctimas.

La primera generación de cristianos creyó, además, que la resurrección de Jesús era el comienzo de la resurrección universal ( $c f r$. 1Tes 4, $15,17$; 1Cor 15,51$)$. Por eso, la resurrección de Jesús fue expresada como la del "primogénito de muchos hermanos" (Rom 8, 29; ICor 15, 13; Col 1, 18; Hech 3, 15; Apoc 1, 5). La resurrección es

15. Jeremías, J., Teologia del Nuevo Testamento I, Salamanca, 1986, p. 147.

16. Aguirre, R., Del movimiento de Jesús a la Iglesia cristiana, Bilbao, 1987, p. 51.

17. Kessler, H., La resurrección de Jesús, Salamanca, 1989, pp. 46-52. 
pensada colectivamente, y la esperanza es, entonces, la esperanza de un pueblo.

Este breve recordatorio de la tradición bíblica ayuda a situar la realidad de la esperanza en la actualidad. En primer lugar, la esperanza acaece en presencia de alguna seria dificultad, y, fundamentalmente, ante la grave dificultad de sobrevivir. La esperanza no es simplemente deseo de que ocurran cosas buenas, ni siquiera de que haya otra vida, sino que es el anhelo de que el mal pueda ser vencido, y, así, de que la vida, la dignidad, la juslicia sea posible.

La esperanza se hace real "en contra" de algo que oprime. Por ello, según la lógica bíblica, la esperanza no es de todos por igual, sino que es, en directo, de los pobres (los que esperan el reino), de las víclimas (los que esperan vida, que el verdugo no triunfe para siempre). No excluye esto, por supuesto, la posibilidad de una esperanza universal, de todos, pero, según lo dicho, los no-pobres, los no-víctimas, tienen que asimilarse de alguna manera, análogamente, a los pobres y víctimas, lo cual puede ocurrir abajándose y solidarizándose con ellos, participando en sus trabajos y destino. Entonces sí pueden tener esperanza. (En el caso de los verdugos y opresores, éstos tienen que pasar antes por la conversión). Hay que distinguir, pues, entre esperanza y deseo. Dicho de la manera más sencilla posible, que "la vida sea posible en Rwanda" es objeto de esperanza, que "se pueda acumular una fortuna" puede ser objeto de deseo, pero no de esperanza.

La esperanza es, pues, de los pobres, de las mayorías populares y de quienes, de alguna manera, se asimilan a ellos. Para ver si en un país la esperanza es importante o trasnochada, qué esperanza debe existir, qué es lo que genera esperanza - no sólo lo que genera expectativas y deseos- hay que poner los ojos en las mayorías, "hacerse cargo de ellas", "encargarse de ellas", "cargar con ellas".

\subsection{El contenido de la esperanza: la utopía de los pobres}

Si nos preguntamos cuál es en concreto la esperanza de los pobres, podemos responder en forma muy general que es "la vida justa y digna abierla siempre a un más". Esa es su utopía. Que la "vida" exprese utopía debiera quedar claro $-y$ así aparece lambién en el Antiguo Testamento y en los sinópticos - por la masividad de la muerte (en las formas crueles de represión y guerras, en las que mueren ante todo los pobres, y en la forma lenta y masiva, tal como lo presenta el PNUD anualmente). El que la vida sea "justa" es también esencial, pues la carencia de vida depende en muy buena parte de la injusticia estructural. $Y$ el que sea "digna" significa que la vida de los pobres no consiste sólo en sobrevivir como miembros de la especie humana, sino que consiste en convivir con todos dentro de la familia humana (de ahí las justas reclamaciones no sólo del "pobre", sino del "otro", la mujer, el indígena, el afroamericano...).

A esta "vida justa y digna" la llamamos utopía, aun sabiendo lo desprestigiado que está el concepto en algunos lugares, y aun concediendo que, aparentemente, la vida parece ser poca cosa para que se la tenga por utopía. Pero insistimos en ello porque la vida es el contenido de la esperanza de los pobres, el mínimo que es el máximo don de Dios, que decía Monseñor Romero, lo bueno (eutopos). Y lo hacemos también con rigor, pues esa

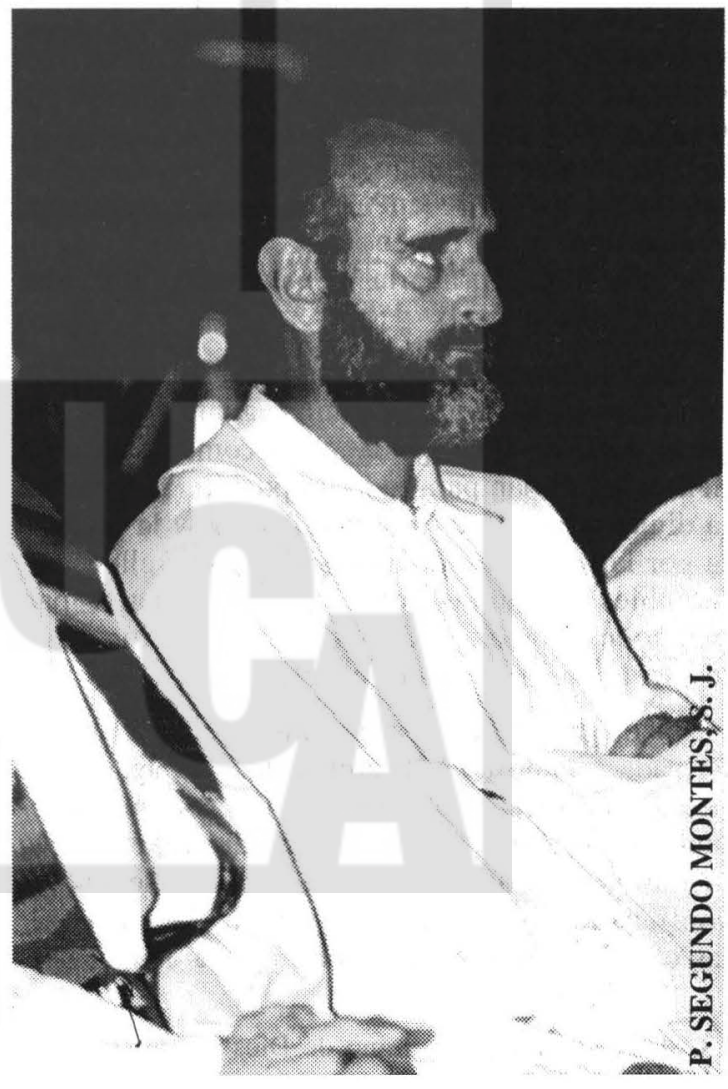


vida digna y justa es aquello para lo que todavía no hay lugar (ou-topos), pero que, no siendo todavía, mueve a trabajar para que llegue a ser.

La "vida", además, es una realidad que por su propia naturaleza está siempre abierta a un "más", es algo dinámico que se desdobla para realizarse a diversos niveles, con nuevas posibilidades y exigencias. La "vida" apunta, entonces, a lo utópico en cuanto plenificante $-y$ de esa forma se puede mantener lo que es típico de la utopía de los pobres: ser a la vez, lo mínimo y lo máximo. Ilustremos el dinamismo de la vida hacia la plenitud con una palabras que escribimos hace años sobre la "fenomenología del pan"18.

La vida comienza con el pan, símbolo primario de vida y de superación de la muerte. Pero ese pan es siempre más que pan. Su misma realidad lleva consigo la pregunta por el cómo conseguirlo, con lo cual se introduce en el pan la dimensión práxica del ser humano. Y una vez conseguido, espontáneamente surge la pregunta por el compartir el pan, $y$ aparece así, a la vez, la dimensión ética del pan (la exigencia a compartirlo), su dimensión comunitaria (el pan en cuanto compartido) y su dimensión celebrativa primaria (comer juntos alrededor de una mesa).

El pan conseguido y compartido por unos se convierte inmediatamente en pregunta por el pan para otros, otros grupos y otras comunidades, en definitiva, el pan para todo un pueblo. Y surge así la dimensión social y política del pan y la pregunta por la liberación de un pueblo, y con ello innumerables preguntas sobre cómo conseguir pan para todos, con qué prácticas, ideologías funcionales, teologías, formas de ser Iglesia...

Nada de esto acaece mecánicamente, sino que en cada estadio de la realidad del pan aparece la necesidad de espíritu: misericordia para que se remuevan las entrañas ante los sin-pan, valentía para luchar por él, fortaleza para mantenerse en los conflictos y persecuciones, verdad para analizar las causas de que no haya pan y para analizar los mejores caminos para superarlas. El pan moviliza, entonces, todas las fuerzas del espíritu humano y le confronta sobre todo con la pregunta de si es o no capaz de amar, de si es capaz o no del mayor amor. Y así el pan propicia entrega, generosidad, heroísmo y hasta el mayor amor de la entrega de la vida.

El pan tiene también algo de sacramental. Así, en El Salvador se celebra la fiesta del maíz, y los que se juntan para celebrarla no sólo comen, sino que cantan y recitan poemas, y esa fiesta genera y expresa comunidad, y produce gozo.

Desde una perspectiva explícitamente religiosa, la buena noticia del pan mueve a agradecer al Dios que lo ha hecho o puede llevar a la pregunta de por qué permite que no haya pan y que no sea compartido. Mueve a seguir al Jesús que multiplicó panes para saciar el hambre o puede llevar a la pregunta de por qué la historia da muerte a hombres como él. Puede llevar a la pregunta de si hay algo más que pan, si hay un pan de la palabra, necesario y buena noticia, incluso cuando no hay pan material, si es verdad que al final de la historia habrá pan para todos y si merece la pena trabajar en la historia por ello, aunque muchas veces la oscuridad lo permee todo, si la esperanza de que haya pan es más sabia que la resignación...

Esta fenomenología del "más" que hay en el pan, sea cual fuere la fortuna de su descripción, sólo pretende mostrar cómo la "vida" se desdobla siempre en "más", pone al ser humano en nuevos y distintos niveles de realidad, y por ello puede fungir, en la práctica, pero también en la teoría, como utopía. El contenido es lo mínimo y lo máx:mo, pero lo que ocurre cuando la utopía es la de los pobres, y no la de cualquiera, es que, aunque la plenitud puede pensarse desde el principio, en la realidad se va desarrollando desde los humildes comienzos de la posibilidad de vida.

Y tal como hemos descrito el proceso, la plenitud que se va consiguiendo poco a poco es humanizante. Esa plenitud no crece en la línea del tener

18. “La centralidad del 'reino de Dios' en la teología de la liberación”, Revista Latinoamericana de Teología, 9. 1985, pp. 274ss. 
más (lo cual parece ser aceptado sin cuestionar), sino en la de ser más. Esta no es la plenitud deseada por el poderoso, ni por el egocéntrico, pero es la plenitud a la que lleva por su naturaleza el mundo de los pobres.

\subsection{La fuerza de la esperanza: una praxis lúci- da, eficaz y agraciada}

Por esperanza se entiende no sólo un contenido, la utopía, sino también el acto mismo de esperar. En este sentido la esperanza es también fuerza, energía, espíritu... Esa fuerza del "esperar" se lleva a cabo conjuntamente con un "saber" y un "hacer" (como enseña Kant), lo cual significa, por una parte, que la esperanza tiene identidad propia y no es reducible ni al saber ni al hacer. Pero, por otra parte, significa que la esperanza no es irracional ni inactiva. No es ignorante (aunque admite la docta ignorancia), ni es puramente expectante (aunque puede estar transida de gracia).

Recordemos, aunque sea muy brevemente, que en la tradición bíblica esperanza no se opone a praxis. Jesús "esperaba" la próxima venida del reino y, sin embargo, dedicó el mayor parte de su tiempo a un "hacer": curaciones, predicación, acogida a los marginados, denuncias... Su esperanza no fue puramente expectante. Tampoco hoy la esperanza de los pobres debe ser comprendida como pura expectativa inactiva, sino que debe ser acompañada de una praxis.

La praxis debe ser lúcida. Por remitirse al futuro de conseguir lo que busca, el no-saber le es ingrediente esencial. Pero eso no quiere decir que no sea lúcida, que no vea la realidad con objetividad - y desde los pobres se puede ver con mayor objetividad-, sus dificultades y posibilidades. En tiempo de Monseñor Romero, la esperanza fue acompañada de mucha lucidez y a su vez iluminó mucho nuestra situación.

La praxis debe ser dialéctica, es decir, la construccion del reino en contra del antirreino. Hay que buscar concertaciones, consensos y convergencias, pero no se puede evitar algún tipo de confrontación -y eso es importante recordarlo hoy. Esperanza que nunca lucha no es esperanza.

La praxis debe ser eficaz, y en esto está la necesidad de simultanear lo que antes decíamos de

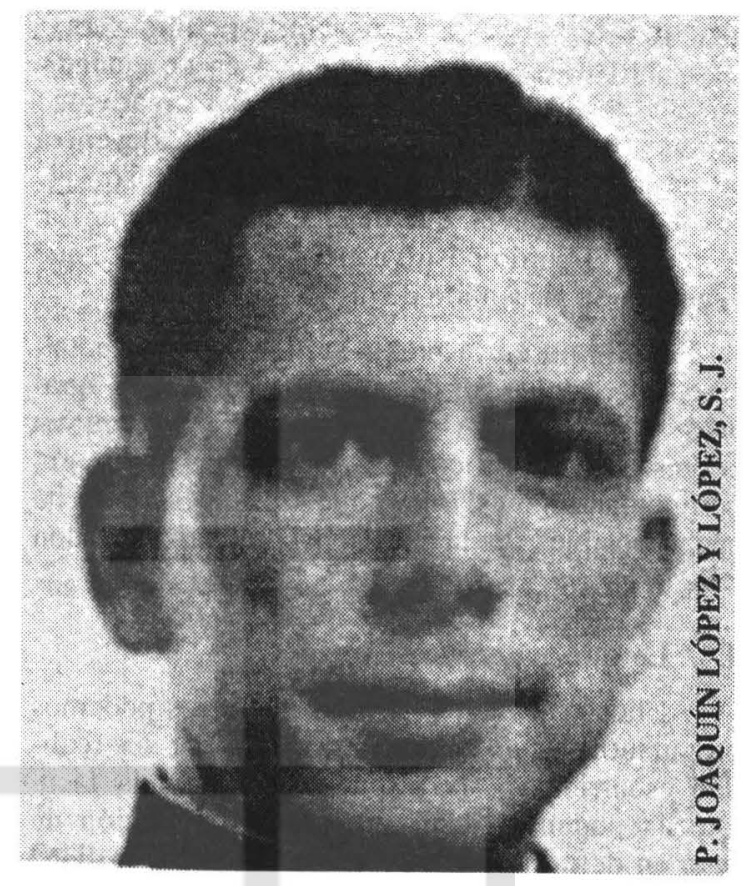

objetividad, realismo, profetismo y utopía. El profetismo y la utopía, por lo que niegan y afirman, son como el motor de la esperanza, lo que llevó a Ellacuría a formular el ideal de una "civilización de la pobreza". Pero a su vez hay que buscar los instrumentos adecuados:

Queda otro paso también fundamental y es el de crear modelos económicos, políticos y culturales que hagan posible una civilización del trabajo como sustitutiva de una civilización del capital. Y es aquí donde los intelectuales de todo tipo, esto es, los teóricos críticos de la realidad, tienen un reto y una tarea impostergables. No basta con la crítica y la destrucción, sino que se precisa una construcción que sirva de alternativa real ${ }^{19}$.

La praxis debe ser humanizante, productora de bienes sociales, no sólo de bienes económicos. No basta dirigir la praxis a la subsistencia de la especie, sino a que sea posible la familia humana. De ahí que la praxis debe construir valores más afines a la civilización de la pobreza que a la actual civilización de la riqueza: comunidad versus individualismo aislacionista, que fácilmente degenera en egoísmo; celebración versus diversión irresponsa-

19. "El desafío de las mayorías populares", ECA, 493-494, 1989, p. 1078. 
ble, que degenera en alienación; apertura versus etnocentrismo cruel, que degenera en desentendimiento del sufrimiento de los otros; creatividad versus imitación servil, que fácilmente degenera en pérdida de identidad propia; compromiso versus mera tolerancia, que degenera en indiferencia; fe versus el burdo positivismo y pragmatismo, que degenera en sinsentido de la vida...

Por último en la praxis se debe experimentar, en cuanto esto es posible, que la esperanza es agraciada. Conseguir los mínimos de vida es para los pobres cosa tan difícil, que cuando eso ocurre experimentan algo así como que "lo imposible se ha hecho posible". Es la experiencia histórica del don y de la gracia.

\subsection{Lo que genera esperanza}

Al llegar al final de estas reflexiones podemos preguntarnos qué es esperanza, y - por ser realidad escurridiza - la respuesta no es nada fácil. Quizás podamos decir que es la convicción de que, en definitiva, y a pesar de todo el bien tiene más poder que el mal, que la historia es promesa bienaventurada más que silencio absurdo, que el amor es más luerte que la muerte, que Dios scrá, al final, todo en todos. En definitiva, que la vida y lo humano es posible.

Cómo se formule la esperanza no es lo más importante. Más eficaz será apuntar a Monseñor Romero, o a los campesinos que huyeron en guinda y regresaron a su tierra, o a las madres de Rwanda que siguen caminando para que sus hijos tengan vida. En delinitiva, la pregunta decisiva es cómo se consigue esperanza, qué la genera. Junto a otras preguntas: dónde encontrar seguridad, dónde encontrar trabajo, dónde encontrar felicidad, los puchlos también se preguntan dónde encontrar esperanza.

La respuesta es muy personal, pero quizás se pucde decir lo siguiente. Allí donde hay bondad, allí crece la esperanza, y la lógica parece ser la siguiente: si en el presente, venciendo graves obsláculos, la bondad es posible, también será posible la bondad en el luturo. Dicho lo mismo con un poco mús de concreción, alli donde hay amor, personas que aman a olras, a veces más que a sí mismas, allí surge la esperanza. El amor es más fuerte que el sulrimicnto, es más fuerte que la muerte, y eso genera esperanza.
La bondad, el amor de las personas, es lo que puede generar esperanza. Pero también los grandes o pequeños logros de esa bondad y ese amor. Dice Medellín que "cuando se pasa de situaciones menos humanas a situaciones más humanas", allí se da el paso del Señor -y algo parecido se puede decir de la esperanza, sólo que, históricamente, ese paso tiene un lugar privilegiado: la comunidad de los pobres, con la solidaridad de quienes no son pobres.

Es una experiencia que se mantiene hasta el día de hoy, aunque no quizás con la brillantez de hace años, que los que están abajo en la historia, cuando se juntan para vivir en comunidad y se organizan para proyectos de la comunidad, de organizar su economía, de vivir su fe cristiana, consiguen logros, mayores o menores, y esos logros producen esperanza, reproducen el milagro de que "lo imposible se ha hecho posible". Reflejan la relación entre esperanza y pobres.

Con frecuencia entonamos las letanías del desencanto: las que nos recuerda el PNUD, las que añadimos nosotros, neoliberalismo, Banco Mundial, Fondo Monetario, deuda externa, niños de la calle, prostitución infantil..., sin olvidar a las Iglesias, a veces distanciadas de los pobres, con falta de derechos humanos en su interior, sin aceptar en serio a la mujer, con poca inculturación en muchas partes...

Pero también hay que entonar las letanías de la esperanza: los innumerables grupos, comunidades, conferencias y seminarios, en el país y en todo el mundo, de derechos humanos y solidaridad, de promoción de la paz y de la ecología, de denuncia de la injusticia y de las violaciones de la vida, de inculturación y diálogo interreligioso... También hay ciertas ganancias - pequeñas, pero ganancias al fin-en cambios estructurales: algunas facilidades que se logran con la democracia, mayores libertades que hace unos años, más diálogos, de los que puede salir más luz... A veces la justicia se impone a la impunidad, y hay juicios a los pinochets del continente. Sobre todo sigue existiendo "la mesa compartida" en muchos lugares y de muchas formas, alrededor de la cual los pobres se sienten pueblo con dignidad, y a esa mesa invitan a todos. De sobra conocemos las letanías de la desesperanza y el desencanto, pero hay que añadir las de la esperanza. Y eso, en sí mismo, genera esperanza. 
Digamos para terminar algo que es decisivo, sobre todo entre pueblos pobres, que han sufrido $y$ siguen sufriendo lo increible. Para generar esperanza hay que tener credibilidad. En otras palabras, la bondad y el amor que hemos mencionado antes, pueden ser una bondad y un amor específicos: se mantienen hasta el final, en presencia de y a pesar de los obstáculos en contra, de los ataques, la persecución y el sufrimiento que sobrevienen, y entonces dan esperanza a los pobres. El amor de quienes comparten su destino y se hacen afines a ellos tiene una credibilidad especial. Y eso da esperanza.

"No toda vida es ocasión de esperanza, pero sí lo es la vida de Jesús, quien, por amor, cargó sobre sí la cruz", dice el teólogo alemán Jürgen
Moltmann. Entre nosotros esto sigue siendo verdad histórica. Por paradójico que parezca, los mártires siguen siendo fuente de esperanza. Quizás no para todos, pero sí para los pobres y para quienes se solidarizan con ellos.

El país, todo el tercer mundo y también el primer mundo, necesitan esperanza. La esperanza humaniza, mientras que su ausencia deshumaniza. Por esa razón, en definitiva, hemos abordado el tema en una cátedra de realidad nacional: porque queremos que el país tenga esperanza, la ponga a producir, supere los males que nos afligen y propicie los bienes que nos humanicen.

La esperanza no sustituye a nada, pero nada sustituye a la esperanza. 